\title{
Ou wyn in nuwe sakke: 'n Kritiese waardering van Bijbels lexicon
}

\author{
Anna Nel Otto, Departement Afrikaans, Universiteit Vista, Port Elizabeth, \\ Republiek van Suid-Afrika (otto-an@pelican.vista.ac.za)
}

Opsomming: Bijbels lexicon is 'n Nederlandse leksikon wat woorde en uitdrukkings bevat wat aan die Bybel ontleen is en wat ná 1945 nog bekend was. Die teikengebruikers van hierdie leksikon is waarskynlik persone wat graag die Bybel lees en diegene wat belangstel in die oorsprong en agtergrond van die Nederlandse taal. Die inleiding tot die leksikon bevat baie inligting, onder andere oor hoe die leksikon saamgestel is, 'n uiteensetting van tipes leksikale items en motivering vir lemmakeuses en tydvak wat gedek word, hoe om leksikale items na te slaan, ens. Selfs niegelowiges sal die leksikon kan gebruik, aangesien die inleiding ook agtergrondsinligting in blokvorm bevat, nl. 'n uiteensetting van die inhoud van die Bybel, en inligting oor Nederlandse Bybelvertalings, spreekwoordversamelings en Bybelse name.

Die voordele van hierdie leksikon is dat dit slegs huidige gebruiksvoorbeelde bevat en daarom dus neologismes en veranderde betekenisse akkommodeer. Hoewel die outeurs in enkele gevalle afwyk van die terminologie vir verskillende tipes leksikale items, soos deur hulle self omskryf, is die hantering van woordeboekartikels oor die algemeen baie konsekwent en inligting is maklik toeganklik. Die waarde van die leksikon sou moontlik verder verhoog kon word deur die gebruik van meer kruisverwysings.

Sleutelwoorde: BETEKENIS, BYBEL, EIENAAM, HEDENDAAGSE GEBRUIK, HERKOMS, LEKSIKOGRAFIE, LEKSIKON, NEDERLANDS, NEOLOGISME, SITAAT, SPREEKWOORD, VASTE UITDRUKKING

\begin{abstract}
Old Wine in New Bottles: A Critical Appreciation of Bijbels lexicon. Bijbels lexicon is a Dutch lexicon which includes words and fixed expressions which have been borrowed from the Bible and which were still known after 1945. The target users of this lexicon are probably people who are fond of reading the Bible and those who are interested in the origin and background of the Dutch language. The introduction to the dictionary contains much information, inter alia on how the lexicon is structured, an exposition of different types of lexical items and motivation for the choice of lemmata and period covered, on how to look up lexical items, etc. Even non-believers could use the lexicon, as the introduction also contains background information in block format, i.e. an exposition of the content of the Bible, and information on Dutch Bible translations, proverb collections and Bible names.

The benefits of this lexicon are that it includes only examples of current usage and as such accommodates neologisms and changed meanings. Although the authors sometimes divert from the terminology for different types of lexical items, as defined by themselves, the treatment of dictionary articles is generally very consistent and information is easily accessible. The value of the lexicon could possibly be enhanced by using more cross-references.
\end{abstract}


Keywords: BIBLE, CITATION, CURRENT USAGE, DUTCH, FIXED EXPRESSION, LEXICOGRAPHY, LEXICON, MEANING, NEOLOGISM, ORIGIN, PROPER NAME, PROVERB

\section{Inleiding}

Bijbels lexicon is 'n Nederlandse leksikon waarin 'n bepaalde seleksie van woorde, uitdrukkings en spreekwoorde opgeneem is wat aan die Bybel ontleen is. Dié seleksie is gebaseer op daardie woorde en uitdrukkings wat ná 1945 nog bekend was.

Die teikengebruikers word nie in die teks self geïdentifiseer nie, maar op die agterblad word wel gesê dat Bijbels lexicon 'n unieke boek is vir elke Bybelliefhebber, gelowig of niegelowig, en dat dit onontbeerlik is vir elkeen wat belangstel in die oorsprong en die agtergrond van die Nederlandse taal.

In verskeie publikasies word die belangrikheid van 'n goed geïdentifiseerde teikengroep en die vasstel van hulle behoeftes beklemtoon. De Schryver en Prinsloo (2000: 1-31) bepleit byvoorbeeld die konsep van "gelyktydige terugvoering", dit is dat terugvoering vanaf die teikengebruikers verkry moet word terwyl die samestelling van die woordeboek nog aan die gang is. In Bijbels lexicon word daar slegs in die voorwoord aangedui dat die outeurs die versoek gekry het om 'n woordeboek saam te stel wat Bybelse woorde en uitdrukkings bevat wat steeds gebruik word. Dit is dus nie duidelik of formele en/of informele marknavorsing gedoen is en wie presies die versoek aan die outeurs gerig het nie.

In 'n navorsingsprojek oor die behoeftes van Bybelgebruikers het die outeur van hierdie artikel bevind dat uit 'n totaal van 29 persone met "religieuse beroepe" slegs 5 persone aangedui het dat hierdie inligting essensieel is in 'n Bybelwoordeboek, terwyl uit 'n totaal van 45 persone met "nie-religieuse" beroepe niemand aangedui het dat hulle hierdie inligting as essensieel beskou nie, hoewel 15 persone aangedui het dat hierdie inligting wenslik is. Die vraag wat in 'n vraelys aan respondente gestel is, lui soos volg: Watter van die volgende inligtingstipes beskou $u$ as essensieel, wenslik of oortollig in 'n Bybelwoordeboek: aanhalings wat die huidige gebruik (ná 1945) van woorde en uitdrukkings uit die Bybel in ander media illustreer, bv. in tydskrifte, boeke, oor die radio, televisie, ens.? Dit wil dus voorkom asof die meeste respondente wat hoofsaaklik Suid-Afrikaners was, nie juis 'n behoefte aan hierdie tipe woordeboek het nie.

\section{Werkwyse}

By die beoordeling van Bijbels lexicon sal daar kommentaar gelewer word op die verskillende dele waaruit die woordeboek bestaan, deur eers aan te dui hoe die woordeboek saamgestel is en deur die kommentaar in dieselfde volgorde hierby aan te bied. 


\section{Die niealfabetiese deel van die leksikon}

\subsection{Die toeligtingsgedeelte}

Dit is verblydend dat die toeligtingsgedeelte so volledig is, afgesien daarvan dat 'n teikengroep of -groepe nie hier eksplisiet genoem word nie. Hierdie deel bestaan uit die volgende afdelings: ' $n$ inleiding, 'n geskiedkundige oorsig waarin beskryf word hoe Bybeltekste Nederlands sedert die vroegste tye beïnvloed het, ' $n$ motivering vir die fokus op hedendaagse gebruik, 'n toeligting oor die verskillende tipes ontlenings, kriteria vir opname, verantwoording van bronne, 'n afdeling wat uiteensit hoe die artikels opgebou is en aanwysings oor hoe om woorde en uitdrukkings na te slaan.

\subsubsection{Die inleiding}

Die inleiding dui die samestelling van die leksikon volledig aan. Daar word eerstens gewys op die feit dat Nederlands baie woorde, uitdrukkings en spreekwoorde het wat aan die Bybel ontleen is. Baie van hierdie woorde en uitdrukkings is egter nie meer bekend nie. Dan word 'n motivering gegee vir die opname van hierdie woorde en uitdrukkings in die leksikon: dit is nie net interessant om hulle agtergrond te ken nie, maar vir die begrip van literêre en ander tekste uit die laaste eeu is dit ook nodig om hulle betekenis en herkoms te ken. Boonop gee hierdie woorde en uitdrukkings ' $n$ beeld van die inhoud en sfeer van die Bybelverhale en daarmee ook van een van die belangrikste tradisionele elemente van die Nederlandse kultuur, aldus die outeurs.

Die inligtingstipes wat in die alfabetiese gedeelte opgeneem is, word uiteengesit en die seleksie van woordeskatitems word aangedui, nl. woorde en uitdrukkings wat sedert 1945 bekend was/steeds is. Dié woordeskatitems is in alfabetiese volgorde opgeneem, voorsien van 'n betekenisverklaring, 'n toeligting oor die herkoms, 'n Bybeluittreksel uit 'n ouer vertaling en laastens enkele sitate ter illustrasie van die huidige gebruik uit verskillende soorte moderne bronne.

Daar word ook uiteengesit watter onderwerpe in die niealfabetiese gedeelte behandel word.

\subsubsection{Die geskiedkundige oorsig oor hoe Bybeltekste Nederlands beïnvloed het}

Interessante feite word in hierdie afdeling vermeld. Slegs enkele feite wat die outeurs noem, word hier uitgelig. Daar word aanvaar dat Christelike leenwoorde al vanaf die agtste en negende eeu ontstaan het. Bestaande Germaanse woorde het nuwe, Christelike betekenisse bygekry: vergelyk woorde soos hel, herder en ziel. Hierdie nuwe Christelike woordeskat het betrekking gehad op kerktaal, soos absolutie, hostie en bisschop, en Bybeltaal, bv. kruis, engel en priester.

Woorde uit Grieks en Hebreeus het meestal via Latyn in Nederlands 
gekom. Voorbeelde is amen en psalm (Hebreeus) en evangelie en apostel (Grieks). Uit onvertaalde Latyn het Nederlands ook enkele name van Bybelboeke (bv. Genesis en Exodus) oorgeneem, en Bybelse verbindings soos die eerste versreëls van gesange of gebede, wat later soms selfs as afsonderlike woorde 'n eie betekenis gekry het (bv. lavabo, 'ik zal wassen', later 'wasbekken').

\subsubsection{Die huidige gebruik}

'n Besliste voordeel van hierdie leksikon is dat die gebruiker verseker word dat slegs huidige gebruiksvoorbeelde opgeneem is. Die outeurs wys dan ook daarop dat daar twee belangrike verskille is tussen dít wat woordeboeke en spreekwoordversamelings ons ten opsigte van idiome, Bybels al dan nie, aanbied en daardie idiome wat werklik gebruik word. 'n Uitsondering is Van Dale Idioom woordenboek van 1999 wat ook net op werklike gebruik gebaseer is.

Eerstens bevat naslaanwerke dikwels verouderde materiaal. As voorbeeld noem die outeurs die herdruk van Huizinga (1998) wat twee uitdrukkings bevat, wat na hulle mening nie meer gebruik word nie, nl. maaien waar men niet gezaaid heeft, 'vruchten plukken van de inspanningen van een ander' en gehoorzamen is beter dan offerande 'het is beter eerst naar een ander te luisteren dan om meteen te handelen'. Die teikengebruikers se behoeftes, in samehang met dié tipe woordeboek, is deurslaggewend vir die opname van verouderde materiaal al dan nie. In 'n omvattende of handwoordeboek verwag gebruikers volledigheid, met dien verstande dat verouderde materiaal as sodanig geëtiketteer behoort te word. Indien daar 'n behoefte bestaan aan 'n woordeboek wat slegs huidige gebruik verteenwoordig, behoort verouderde materiaal uit die aard van die saak nie in so 'n woordeboek opgeneem te word nie.

Die outeurs merk tereg op dat daar 'n besliste afname is in mense se kennis van die Bybel. Bybeltekste word nie maklik meer spontaan aangehaal nie. Ook het die spontane vernoeming van voorwerpe na Bybelse persone of plekke sterk afgeneem. Hulle wys ook daarop dat veroudering saamhang met taalkringe. Wat uit die algemene Nederlands verdwyn het, kan in bepaalde Christelike kringe nog algemeen wees.

'n Tweede groot verskil tussen dít wat opgeneem is in woordeboeke en spreekwoordversamelings en die werklike gebruik daarvan, is die baie variasie ten opsigte van vorm by werklike gebruik. As daar in die woordeboeke in goede aarde vallen staan, dan tref ' $\mathrm{n}$ mens in die praktyk ook vruchtbare aarde aan, en vir die teenoorgestelde betekenis verkeerde of dorre aarde. Dit gebeur ook soms in die praktyk dat elemente van uitdrukkings weggelaat word, bv. te licht bevonden naas gewogen en te licht bevonden. Volgens die outeurs ontstaan analogieë ook soms in die praktyk: de ware Jakob lei tot de ware Jakoba en Sara zien kom naas Abraham zien voor.

Daar is nie net 'n groot mate van variasie ten opsigte van vorm nie, maar ook die reikwydte van toepassing val op. Baie woorde en uitdrukkings wat uit 'n ernstige Bybelgedeelte kom, kan gemaklik in 'n wêreldse konteks gebruik 
word, bv. de geest is wel gewillig, maar het vlees is zwak. 'n Ironiese gebruik van hierdie uitdrukking kry 'n mens in Jan Wolkers se roman Een roos van vlees (p. 11) waar die hoofkarakter daarop wys dat hy wel 'n gesonde liggaam en 'n gesonde gees behoort te hê vanweë die gimnastiek wat hy beoefen, maar besef dat hy eintlik 'n ongesonde gees in 'n gesonde liggaam het: "Het vlees is wel gewillig, maar de geest is zwak." Dat die gebruik van die naam van Jezus in die informele vergelyking zo lui als het paard van Jezus redelik resent is, sou volgens die outeurs dalk verklaar kon word op grond van die gebrekkige optekening van die informele of plat spreektaal.

In literêre tekste vind 'n mens sowel ingeburgerde uitdrukkings, soms met kreatiewe variante, as meer regstreekse verwysings na 'n Bybelteks of aanhaling daaruit, waarby dit om die Bybelse inhoud gaan. Vergelyk weer eens enkele voorbeelde uit bogenoemde roman van Jan Wolkers:

Eet, drink, dit is mijn bloed hetwelk voor u vergoten is. (p. 10)

Daar ligt vlees van mijn vlees. (p.14)

Dood waar is uw prikkel, denkt hij. (p. 28)

Wat die politici betref, neem Bybelse taal ook by hulle af. Volgens die outeurs is dit jammer, want hulle hou uitdrukkings soos iemands nieren proeven en een tocht door de woestijn lewend en het gebruike soos die volgende in die taal gebring: bergrede vir 'rede over sociale politiek'.

\subsubsection{Toeligting by die verskillende tipes ontlenings}

Dit is belangrik dat leksikograwe 'n duidelike omskrywing gee van die verskillende tipes woordeskatitems wat in 'n woordeboek opgeneem word en dan konsekwent by hierdie omskrywings bly. In hierdie afdeling gee Bijbels lexicon 'n omskrywing van die terminologie wat gebruik word. Die term uitdrukking word gedefinieer as "een vaste verbinding van twee of meer woorden met een eigen betekenis". Onder die term uitdrukking moet ook spreekwoorde verstaan word. Hoewel Bijbels lexicon dus nie formeel 'n onderskeid tref tussen dít wat hulle "uitdrukkings" noem en spreekwoorde nie, omskryf hulle wel die term spreekwoord, soos hulle dit verstaan: "een levenswijsheid in de vorm van een volzin, die ook zonder context betekenis heeft."

Daar bestaan ' $n$ wye verskeidenheid terme vir die begrip vaste uitdrukking of vaste verbinding. Gouws (1989: 98) beskryf vaste uitdrukkings as geykte komplekse leksikale items. Hulle is geleksikaliseerde eenhede met ' $n$ betekenis wat nie sonder meer afleibaar is van dié van die samestellende dele nie. Vaste uitdrukkings en spreekwoorde verskil dus in dié opsig dat spreekwoorde se betekenisse wel deursigtig is. Verstraten (1992: 12) definieer die term vaste verbinding soos volg: "een vaste verbinding is een combinatie van minimaal twee lexicale elementen (woorden), die als gefixeerd geldt." Vastheid, al dan nie, word bepaal deur die terme komposisionaliteit, deursigtigheid, gemotiveerdheid en idiomatisiteit. 
Die begrip komposisionaliteit het betrekking op die wyse waarop die betekenis van die vaste verbinding opgebou is: indien die betekenis beskou kan word as ' $n$ optelsom van die betekenisse van die samestellende dele, dan het 'n mens te make met ' $n$ komposisionele betekenis.

Die deursigtigheid van die verbinding is afhanklik van die mate waarin die taalgebruiker in staat is om raak te sien op watter wyse die betekenis van die verbinding uit dié van die samestellende dele tot stand gekom het. Die komposisionaliteit van 'n verbinding kan 'n invloed hê op die deursigtigheid daarvan. Deursigtigheid is egter 'n subjektiewe begrip, want dit is sterk afhanklik van die individuele kennis van die taalgebruiker.

Die begrip gemotiveerdheid word soos volg deur Lakoff (1987: 448) omskryf: "The relationship between A and B is motivated just in case there is an independently existing link L, such that A-L-B 'fit together'. L makes sense of the relationship between A and B."

Verstraten (1992: 14) beskou idiomatisiteit en ondeursigtigheid in beginsel as dieselfde.

Daar is egter nie altyd sprake van net twee kategorieë, nl. woorde of uitdrukkings, wat in Bijbels lexicon opgeneem is nie. By die lemma aanstoot staan die volgende:

Aanstoot, iets waaraan men zich stoot; (fig.) persoon of zaak die ergernis of morele verontwaardiging wekt. Steeds in de volgende uitdrukkingen.

Aanstoot geven, morele ergernis opwekken.

Aanstootgevend, ergerniswekkend, kwetsend.

Aanstoot nemen aan, zich ergeren aan; als kwetsend beschouwen.

Steen des aanstoots, iets waaraan men zich ergert, oorzaak van ergernis.

Die sogenaamde uitdrukkings aanstoot geven en aanstoot nemen aan is eerstens kollokasies (aangesien die dele komposisioneel en deursigtig is) en nie uitdrukkings nie. Tweedens is die kollokasies nie konsekwent gehanteer nie. Die setsel aan sou eweneens, net soos by aanstoot nemen (aan), by aanstoot geven (aan) kon optree.

Dit is belangrik dat uitdrukkings korrek en volledig met betrekking tot variante vorme opgeneem word. By die lemma Abraham word onder andere die volgende uitdrukkings aangegee: aan Abrahams borst of in Abrahams schoot rusten. Die korrekte vorme is egter: aan Abrahams borst rusten of in Abrahams schoot zitten, soos aangedui in Bijbels lexicon se voorbeeldsinne en bevestig deur Grote Van Dale en Spreekwoorden verklaard.

Die volgende tipes ontlenings word in die niealfabetiese deel van Bijbels lexicon onderskei:

\section{(a) Woorde en uitdrukkings wat afkomstig is van 'n Bybelvertaling}

Die outeurs verduidelik hierdie kategorie soos volg: dit is afkomstig van 'n Bybelvertaling en kon 'n gewysigde, byvoorbeeld figuurlike betekenis gekry het of het die reeds bestaande figuurlike betekenis behou, soos aanfluiting, jubeljaar, 
manna en talent. Afleidings en samestellings word ook aangedui, bv. profeteren en profetie asook onheilsprofeet en weerprofeet onder profeet.

Nuutskeppings op basis van woorde wat uit 'n Bybelvertaling afkomstig is, sluit die volgende kategorieë (met voorbeelde daarnaas) in: afleidings: evangeliseren, paradijselijk; samestellings: aanstootgevend, vredesapostel; uitdrukkings: apostel van $x$, geen jota van iets begrijpen. Voorbeelde van uitdrukkings wat in die geheel op 'n Bybelse formulering teruggaan, is talryk: naar de letter, met bezemen keren, zich niet onbetuigd laten, het is volbracht. 'n Spesiale vorm het beginwoorde van gebede of liedere soos Onzevader, Weesgegroet en, uit die Latyn, lavabo. Spreekwoorde, bv. aan de vruchten kent men de boom en een goede buur is beter dan een verre vriend, kom blykbaar meestal in mondelinge taalgebruik voor.

\section{Kommentaar op grond van 'n eie steekproef}

Dit is interessant dat die woord Pasen as lemma opgeneem is en dat daar in die verduideliking na paasfeest verwys word, maar dat paasfeest nie as lemma met ' $n$ kruisverwysing na Pasen aangedui word nie. Vergelyk die volgende voorbeeld:

Na de begrensde en behaaglijke sfeer van de gevangeniscel, ... waar wij ons om de honger te stillen overgaven aan fantasieën rond het paasfeest, bevond ik me in een wereld van ruime afmetingen. (NWT 16(3): 34, 1999)

Dit is eweneens nie duidelik waarom schepping as lemma opgeneem is, maar nie Schepper nie. By schepping word bloot terloops verwys na Schepper. Vergelyk enkele bewyse vir die hedendaagse gebruik van Schepper:

Losgerukt van het continent waar witte ladders omhoogrezen tot de troon van de Schepper, vond ik mezelf terug op een eiland. (NWT 16(3): 40, 1999)

God (heeft) ons naar Zijn beeld en gelijkenis geschapen, en zoals de Schepper zich verhoudt tot zijn schepping, zo verhoudt de scheppende mens, de kunstenaar, zich tot zijn kunstwerk. (NWT 16(3): 51, 1999)

\section{(b) Nuutgevormde woorde en uitdrukkings vir begrippe uit die Bybel}

Volgens die outeurs bestaan hierdie kategorie uit taalvorme wat nie letterlik so in 'n Bybelvertaling voorkom nie, maar wel Bybelse sake benoem. Die herkoms is nie altyd duidelik nie. Hulle kon moontlik in die spreektaal ontstaan het en hulle word reëlmatig deur uitgewers van Bybelvertalings gebruik in inleidende tekste of samevattings by die eintlike Bybelteks of as hoofstuktitel. Woorde uit hierdie groep is: bergrede, beschermengel, kruiswoord en zondeval; uitdrukkings: de tien geboden, verloren paradijs, verboden vrucht en de verloren zoon.

\section{Kommentaar op grond van 'n eie steekproef}

Die woord kruisweg is as samestelling onder die lemma kruis opgeneem. Hoewel kruistog nie direk van Bybelse herkoms is nie, sou 'n mens by kruisweg ' $\mathrm{n}$ 
verwysing na kruistog waardeer ten einde die verskille tussen die twee woorde se betekenisse en herkoms aan te dui. Hier volg enkele voorbeelde ter illustrasie van kruistog:

In 1984 lanceerde dit instituut Losing Ground, het werk van Charles Murray dat de bijbel zou worden van Reagens kruistocht tegen de verzorgingsstaat. (NWT 16(8): 60, 1999)

In die omstandigheden is het moeilijk om een kruistocht voor radikale vernieuwing te voeren, zelfs als het grootste deel van het kiezerscorps het leven permanent somber lijkt in te zien. (NWT 16 (1):12, 1999)

Op 'n min of meer soortgelyke wyse sou 'n mens by Kerst 'n sublemma kerstdag wou hê, soos geillustreer in die onderstaande voorbeeld:

Ik begon over "A Child's Christmas in Wales". Het verhaal van Dylan Thomas, waarop het liedje is gebaseerd, gaat over een idyllische kerstdag uit Thomas' kindertijd. (NWT 16(1): 25, 1999)

\section{(c) Eiename}

Hierdie kategorie betrek name van persone en plekke, genoem in gestandaardiseerde of niegestandaardiseerde uitdrukkings (bv. zo arm als Job, naakt als Eva), as simbool of as metafoor (bv. Benjamin, Babylon). Soms is daar ook persone in stereotiepe voorstellings, bv. Petrus aan de hemelpoort, wat nie 'n vaste uitdrukking is nie, maar dikwels as sodanig saamgebruik word. Van Bybelname word afleidings gevorm, wat dan wel opgeneem word, bv. jeremiade (van Jeremia), onaneren (van Onan), verdere samestellings soos adamsappel, salomonsoordeel en uitdrukkings soos Job op de mestvaalt, ongelovige Tomas. Laastens is daar ook kombinasies van name, soos Adam en Eva, David en Goliat, wat nie altyd so in kombinasie in die Bybel self genoem word nie.

Dit wil voorkom asof persoonsname redelik volledig opgeneem is. So is byvoorbeeld die volgende bewys gevind dat Lazarus steeds gebruik word:

Ik haal mijn handen over mijn christelike gezicht om de bleekheid te verdrijven die me overviel bij het zien van deze Lazarus die nog rook naar de joodse dood. (NWT 16(3): 31, 1999)

In die volgende voorbeeld word twee persoonsname, nl. Salomon en Hiram, genoem. Salomon is tereg opgeneem, maar Hiram nie. Dit kan toegeskryf word aan die feit dat Hiram nie in 'n uitdrukking gebruik word nie en nie 'n metaforiese of simboliese betekenis het nie, terwyl daar algemeen na die wysheid van Salomo verwys word in die omgangstaal:

In mijn sarmatische ... boot roei ik naas hun cederhouten vlot, van het hout dat Hiram aan Salomon stuurde om hem te behagen. (NWT 16(3): 31, 1999)

Al verbetering wat ' $\mathrm{n}$ mens sou kon aanbring, is om die wisselvorm Salomon, naas Salomo, reeds by die lemma te gee, waar slegs die vorm Salomo opgeneem 
is. Eers in die derde paragraaf word aangedui dat Salomon 'n ouer vorm van Salomo is.

Dit is opvallend dat die persoonsnaam Delila nie opgeneem is nie. In Grote Van Dale (Lys van Bybelse name in Aanhangsel III) staan daar by Delila: "Filistijnse vrouw die als minnares van Simson hem in handen speelt van de Filistijnen, na hem het geheim van zijn kracht ontlokt te hebben (Richt. 16: 4)." In Verklarend Handwoordenboek der Nederlandse Taal is Delila opgeneem en soos volg verklaar: "1 vrouw van Simson, een Filistijnse (bijb. Richt. 16); 2 (fig.) verleidelijke, trouweloze vrouw." Na my beste wete was Delila slegs Simson se minnares en het die woord vandag nog die figuurlike betekenis "verleidelike, listige vrou". In Bijbels lexicon by die artikel Simson word Delila Simson se vrou genoem.

Wat die spelling van eiename betref, sou 'n mens soms meer wisselvorme verwag of is die spelling waarskynlik foutief, aangesien dit nie ooreenstem met die spelling in die voorbeelde nie. Vergelyk Thomas wat in Bijbels lexicon Tomas gespel word, maar waar al die voorbeeldsinne die spelling Thomas het.

Die naam Jesaja het by die Katolieke die vorm Isaias, gevolglik behoort hierdie vorm ook opgeneem te word.

Objektiwiteit word meestal gehandhaaf deurdat sowel woorde en uitdrukkings uit die kanonieke as apokriewe boeke opgeneem word. Die woord Susanna en die uitdrukking een kuise Susanna uit 'n apokriewe boek is byvoorbeeld wel opgeneem, maar die spelling verskil van dié van Grote Van Dale, wat Suzanna en een kuise Suzanna met 'n z-spelling vermeld. Dit kan gebruikers verwar.

\section{(d) Sitate}

Daar is ook woorde en uitdrukkings wat, net soos die eiename hierbo beskryf, tot die taalgemeengoed behoort. Toevallig gebruikte Bybelse frases kom soms voor. Hulle word aangehaal as die woorde van iemand anders. Soms gaan hierdie aanhalings gepaard met 'n globale bronvermelding, bv. zoals de bijbel zegt, soms is dit presieser, soos in die volgende voorbeeld: Niet alles wat toegestaan is, is wenselijk, om maar eens met Paulus te spreken. As so 'n uitspraak uit meer as een bron bekend is, en aangehaal word in 'n algemene konteks, dus van toepassing is op 'n nie-Bybelse situasie, dan is hierdie uitspraak in die Bijbels lexicon opgeneem. Die rede hiervoor is dat hierdie uitsprake onderweg na 'n volwaardige uitdrukking kan wees. Regstreekse Bybelsitate met presiese bronvermelding is uit die aard van die saak nie opgeneem nie. Ook die sitate sonder bronvermelding vorm 'n problematiese kategorie, veral aangesien bepaalde literêre outeurs na hartelus in Bybelse woorde praat.

\section{Kommentaar op grond van 'n eie steekproef}

Die bogenoemde kategorie kan geldig wees, soos bewys deur die volgende voorbeeld: 
Waarom zouden we niet samen met koning Salomo zeggen: voor alles is een tijd. (NWT 16(8): 15, 1999)

En 'n mens wonder dan waarom slegs die gestandaardiseerde uitdrukkings Er is een tijd van (een bepaald bezigheid) en van (de tegenovergestelde bezigheid) en Er is een tijd van komen en er is een tijd van gaan opgeneem is in Bijbels lexicon. Minstens in Afrikaans hoor ' $n$ mens gereeld die uitdrukking vir alles is daar ' $n$ tyd (en ' $n$ plek) en die feit dat dit gebruik word, is ook bevestig in 'n redakteursbrief in die tydskrif rooi rose van Februarie 2003, p. 8.

Die problematiek rondom die opname, al dan nie, van bogenoemde kategorie, blyk uit 'n voorbeeld soos die volgende, wat myns insiens waarskynlik 'n geïsoleerde geval verteenwoordig:

Dank u, Heer, dat ik niet ben als zij. (NWT 16(8): 54, 1999)

Dit laat 'n mens onmiddellik Lukas 18: 11 in herinnering roep, wat soos volg in 'n Afrikaanse vertaling lui:

Die Fariseër het gaan staan en by homself so gebid: "O God, ek dank U dat ek nie soos ander mense is nie: diewe, bedrieërs, egbrekers, en ook nie soos hierdie tollenaar nie."

'n Ander problematiese geval is als 't God belieft, wat nie in Bijbels lexicon opgeneem is nie en voorkom in die volgende voorbeeld:

Op de tweede dag van de tweede maand van het jaar tweeduizend zal een klein meisje, als 't God belieft, haar tweede verjaarsdag vieren. (NWT 16(8): 54, 1999)

Die outeurs het waarskynlik nie hierdie uitdrukking opgeneem nie, aangesien hulle dalk nie bewyse van Bybelse herkoms kon vind nie. Die naaste uitdrukking hieraan waaroor inligting opgespoor kon word wat op 'n moontlike Bybelse herkoms dui, is Deo volente waaroor in die woordeboekartikel van Deus (in Grote Van Dale, p. 637) die volgende inligting verskaf word: "Deo volente (D.V.), zo het God behaagt, zo God wil (slechts éénmaal in de bijbel: Acta Apostolorum 18: 21)." Deo Volente is wel in Bijbels lexicon opgeneem.

Om dieselfde rede is die woord bekeerd waarskynlik nie opgeneem nie. Vergelyk die onderstaande voorbeeld:

Ik ben niet bekeerd, of juist wel, net hoe je het bekijkt. Ik geloof, maar ik zwijg daar het liefst over. (NWT 16(8): 31, 1999)

Stam (2002: 4) haal Karina van Dalen-Oskam aan in hierdie verband: "Als wij niet zeker wisten of een uitdrukking aan de Bijbel was ontleend," en "omdat je die ook al in een heel vroeg stadium in wereldlijke teksten tegenkwam, namen wij het woord niet op. Het is dus verklaarbaar dat $u$ een woord als 'bekering' mist. Wij wilden puur registreren." Samewerking tussen leksikograwe, etimo- 
loë en teoloë sou waarskynlik tot groter sekerheid oor problematiese gevalle kon lei. In hierdie verband beklemtoon Tarp (2000: 201) samewerking tussen leksikograwe en vakspesialiste.

Ten opsigte van al hierdie kategorieë woorde en uitdrukkings sou 'n mens meer kruisverwysings wou hê ten einde verbande tussen lemmata makliker raak te sien. By Abraham is daar wel 'n verwysing na Sara en omgekeerd. Kruisverwysings tussen die volgende lemmata sou verhelderend optree: antichrist en beest, apostel en discipel, Beёlzebul en duivel, Geest, God en Christus, ens.

\section{Kriteria vir opname}

Die leksikon bevat slegs woorde en uitdrukkings vir sover hulle ná 1945 nog bekend was. Die outeurs wys daarop dat daar in hierdie periode belangrike maatskaplike veranderinge plaasgevind het, soos vernuwing in die kuns en literatuur en toenemende ontkerkliking. Dit is ook belangrik dat daar aan die begin van hierdie periode ' $n$ nuwe Protestantse Bybelvertaling verskyn het, die NBG-vertaling van 1951, soos die verantwoording dit stel.

\section{Verantwoording van bronne}

Stam (2000: 2) wys tereg daarop dat Bijbels lexicon 'n boeiende boek geword het omdat dit uit so 'n breë spektrum bronne put. Benewens die vele Bybelvertalings en gesaghebbende handboeke, is daar ook 'n groot versameling literatuur, wat wissel van Baantjer tot Van Zomeren en van Het grote kamerplantenboek tot die Tuinfluiter-Trilogie.

Die sitate uit koerante en uit die politiek kom byna almal uit die 27 miljoen koerantkorpus en die 38 miljoen woordkorpus van die Instituut voor Nederlandse Lexicologie in Leiden, waaraan albei outeurs verbonde is. Vanweë die beperkings van die korpus word daar dikwels aangehaal uit NRC Handelsblad, die Meppeler Courant en De Standaard en selfs een keer uit Playboy, maar slegs selde uit Trouw, Nederlands Dagblad of Reformatorisch Dagblad. "Zodoende konden wij overigens duidelijker maken dat aan de Bijbel ontleende uitdrukkingen ook echt algemeen en in meer wereldlijke lectuur gebruikt worden," aldus Karina van Dalen-Oskam (Stam 2000: 2-3).

Stronks (2000: 1) lewer kritiek op die feit dat "een weinig representatiewe bron" soos die Meppeler Courant heel dikwels aangehaal word, daar verwys word na bronne soos geselsies en telefoongesprekke wat nie nagegaan kan word nie, en daar nie erkenning gegee word aan die verskille in die Noord- en Suid-Nederlandse taalsituasie nie.

Aangesien die outeurs streng kriteria het vir opname, kan daar verwag word dat sekere bronne waarskynlik prominenter as ander sal figureer. En dit is verblydend dat die spreektaal ook in ag geneem is. By baie woordeboeke ontbreek neologismes soms juis omdat die spreektaal nie voldoende in aanmerking geneem word nie. 


\section{Slot}

Bijbels lexicon is inderdaad 'n boeiende boek wat in terme van die kriteria vir opname en hantering van artikels so konsekwent en volledig moontlik saamgestel is. Slegs enkele inkonsekwenthede kom voor. Dit bied baie interessante inligting en 'n mens kan verrassende ontdekkings maak, byvoorbeeld deur vas te stel dat 'n uitdrukking soos op die hande dra van Bybelse herkoms is. Uit Bijbels lexicon kan 'n mens ook aflei hoe betekenisse met verloop van tyd verander het, bv. vele zijn geroepen, maar weinigen uitverkoren het deesdae in Nederlands die betekenis dat baie mense in bepaalde beroepe belangstel, maar dat min van hulle hiervoor geskik is. By gebrek aan 'n soortgelyke woordeboek in Afrikaans, kan Afrikaanse lesers beslis baat vind by die lees van hierdie leksikon, aangesien die betekenisse van woorde en uitdrukkings in Nederlands dikwels ooreenstem met hulle Afrikaanse ekwivalente.

\section{Bibliografie}

\section{Algemene bronne}

De Schryver, Gilles-Maurice en D.J. Prinsloo. 2000. The Concept of "Simultaneous Feedback": Towards a New Methodology for Compiling Dictionaries. Lexikos 10: 1-31.

Gouws, R.H. 1989. Leksikografie. Pretoria/Kaapstad: Academica.

Lakoff, G. 1987. Women, Fire and Dangerous Things: What Categories Reveal about the Mind. Chicago: Chicago University Press.

Stam, A. 2000. De frisheid van eeuwenoude folianten [aanlyn]. Beskikbaar: <http://oud.refdag.nl/ boek/boekgs/001227boekgs02.html>. 27 Desember 2000.

Stronks, Els. 2001. Resensie van Bijbels lexicon [aanlyn]. Beskikbaar: <http://www.leidenuniv.nl/ host/mnl/tntl/117/117-3/stronks.htm>.

Tarp, Sven. 2000. Theoretical Challenges to Practical Specialised Lexicography. Lexikos 10: 189-208.

Van Dalen-Oskam, Karina en Marijke Mooijaart. 2000. Bijbels lexicon: Woorden en uitdrukkingen uit de bijbel in het Nederlands van nu. Amsterdam: Prometheus.

Verstraten, Linda P. 1992. Vaste verbindingen: Een lexicologische studie vanuit cognitief-semantisch perspectief naar fraseologismen in het Nederlands. Amsterdam: L.P. Verstraten.

\section{Woordeboeke en spreekwoordversamelings}

Apeldoorn, C.G.L. en R. van Riet. 1999. Spreekwoorden verklaard. Utrecht: Het Spectrum B.V.

De Groot, H. (Hoofred.). 1999. Van Dale Idioom woordenboek. Utrecht/Amsterdam: Van Dale Lexicografie/The Readers Digest.

Geerts, G. en H. Heestermans in samewerking met C.A. den Boon en E.C.M. Vos. 1992 ${ }^{12}$. Van Dale Groot Woordenboek der Nederlandse Taal. Etimologie deur P.A.F. van Veen in samewerking met N. van der Sijs. Utrecht/Antwerpen: Van Dale Lexicografie.

Koenen, M.J. en J.B. Drewes. 1977. Verklarend Handwoordenboek der Nederlandse Taal. Pretoria/ 
Kaapstad: Academica.

Kruijssen, A. e.a. (Reds.). 19984. Huizinga's spreekwoorden en gezegden: Herkomst, verklaring en vergelijking met Frans, Duits en Engels. Baarn: Trion.

Odendal, F.F. en R.H. Gouws (Reds.). 2000. Verklarende Handwoordeboek van die Afrikaanse Taal. Midrand: Perskor.

\section{Bybelvertalings}

Die Bybel: Nuwe vertaling. 1986. Goodwood: Bybelgenootskap van Suid-Afrika.

NBG-vertaling. 1951. Bijbel met deuterocanonieke of apocriefe boeken. Vertaling in opdracht van het Nederlands Bijbelgenootschap bewerkt door de daartoe benoemde commissies. Haarlem/ Brussel: Nederlands Bijbelgenootschap/Belgisch Bijbelgenootschap, 1989 (eerste druk 1951).

\section{Ander bronne}

\section{Boeke}

Wolkers, Jan. $1981^{28}$. Een roos van vlees. Amsterdam: Meulenhoff.

\section{Tydskrifte}

De Schaepdrijver, Sophie. 1999. Stapvoets en rugwaarts de toekomst in. Nieuw Wereldtijdschrift 16(8): 52-56, Oktober 1999.

De Swardt, Liezl. 2003. Hoogskop met die blink skoene (redakteursartikel). rooi rose, Februarie 2003: 8.

McElvoy, Anne. 1999. De macht van het midden. Nieuw Wereldtijdschrift 16(1): 10-15, Februarie 1999.

Meeuse, Piet. 1999. Reproduction interdite. Nieuw Wereldtijdschrift 16(3): 48-61, April 1999.

Otten, Christine. 1999. Terug naar de altviool. Nieuw Wereldtijdschrift 16(1): 22-31, Februarie 1999.

Pankowski, Marian. 1999. De planeet Auschwitz. Nieuw Wereldtijdschrift 16(3): 30-40, April 1999.

Stout, Gerard. 1999. Wrak vee. Nieuw Wereldtijdschrift 16(8): 28-37, Oktober 1999.

Van Istendael, Geert. 1999. Een dag in het paradijs. Nieuw Wereldtijdschrift 16(8): 10-25, Oktober 1999.

Wacquant, Loic. 1999. De ideologie van de onveiligheid. Nieuw Wereldtijdschrift 16(8): 58-65, Oktober 1999. 